\title{
Evaluasi Timbulnya Genangan Pada Catchment Area Sistem Pematusan Greges Yang Dilayani Rumah Pompa Greges Di Rayon Genteng Surabaya
}

\author{
Januar Catur Putranto dan Mas Agus Mardyanto \\ Jurusan Teknik Lingkungan, Fakultas Teknik Sipil Dan Perencanaan, Institut Teknologi Sepuluh Nopember (ITS) \\ Jl. Arief Rahman Hakim, Surabaya 60111 Indonesia \\ e-mail: mardyanto@enviro.its.ac.id
}

\begin{abstract}
Abstrak- Sistem Pematusan dengan luas total 1520 ha. yang dilayani oleh Rumah Pompa Greges mempunyai 1 saluran primer yaitu saluran primer Kali Greges. Saluran primer Kali Greges dengan panjang mencapai 4-5 km dan lebar 12-22 meter merupakan muara dari 17 saluran sekunder. Selain rumah pompa Greges yang melayani saluran primer Kali Greges, terdapat 3 rumah pompa yaitu rumah pompa Dupak Bandarejo yang melayani saluran sekunder Kali Dupak, rumah pompa Asem Jaya yang melayani saluran tersier Kali Asem Jaya, serta rumah pompa Tidar di saluran tersier Petemon Kali yang tidak di operasikan lagi.

Variabel penelitian yang digunakan yaitu kapasitas pompa, debit aliran ke saluran primer, dan debit aliran ke saluran sekunder. Metode yang digunakan yaitu dilakukan perhitungan hidrolika untuk mengetahui debit saluran rencana dan debit eksisting. Selain itu, dilakukan perbandingan terhadap kapasitas pompa saat ini dan kapasitas awal serta dilakukan analisis terhadap Standard Operating Procedure (SOP) pengoperasian pompa.

Hasil evaluasi ini menunjukkan kondisi eksisting 5 segmen saluran sekunder yaitu Kali Tembok Gede, Kali Semarang, Kali Margo Rukun, Kali Demak Timur, dan Kali Dupak tidak mampu melayani debit limpasan air hujan yang disebabkan karena adanya sedimen. Selain itu, juga tidak adanya Standard Operating Procedure (SOP) pengoperasian pompa secara tertulis, sehingga menyebabkan terjadinya genangan dengan luas total genangan 5,71 ha dengan lama waktu genangan maksimum 240 menit dan tinggi genangan maksimum 40 centimeter pada tanggal 16 April 2016 yang merupakan salah satu genangan terbesar di catchment area Sistem Pematusan Greges.
\end{abstract}

Kata Kunci- Genangan, Rayon Genteng, Rumah Pompa Greges, Saluran Primer Kali Greges, Sistem Pematusan Greges

\section{PENDAHULUAN}

$\mathrm{K}$ ota Surabaya sebagai salah satu satu kota pesisir dengan kondisi topografi rendah yaitu berkisar antara 3-6 meter diatas permukaan air laut menyebabkan Kota Surabaya rentan terhadap bencana banjir atau genangan [2]. Sementara itu, faktor lain penyebab banjir atau genangan di Kota Surabaya adalah perubahan tata guna lahan yang terjadi secara pesat [3]. Dengan kondisi tersebut maka sudah tidak mungkin lagi beban drainase Kota Surabaya ditambah oleh perkembangan perubahan lahan yang mengakibatkan kerentanan, sehingga sarana dan prasarana drainase ini perlu ditingkatkan seiring dengan kebutuhan kota agar terbebas dari banjir atau genangan yang menyebabkan terganggunya aktifitas penduduk [5].
Salah satu program dalam mengurangi permasalahan genangan di Kota Surabaya adalah Surabaya Drainage Master Plan 2018 (SDMP 2018). Aplikasi dari program tersebut yaitu dengan melakukan pembagian rayon atau sistem drainase, rehabilitasi saluran, pengalihan arus aliran banjir ke saluran lintas, bozem, dan rumah pompa. Salah satu sistem pematusan Kota Surabaya di Rayon Genteng adalah Sistem Pematusan Greges. Menurut Dinas Bina Marga dan Pematusan, ketika musim penghujan tahun 2015 wilayah Sistem Pematusan Greges merupakan wilayah dengan genangan terluas di Kota Surabaya seluas 11,83 ha yang tersebar di 13 titik [4].

Salah satu cara untuk mengetahui penyebab timbulnya genangan di wilayah Sistem Pematusan Greges adalah dilakukan evaluasi terhadap kapasitas saluran eksisting dalam melayani debit limpasan air hujan dan analisis Standar Operational Procedure (SOP) Pengoperasian Pompa di Rumah Pompa, sehingga permasalahan genangan yang muncul pada catcment area Sistem Pematusan Greges yang dilayani Rumah Pompa Greges dapat terselesaikan.

\section{URAIAN PENELITIAN}

\section{A. Identifikasi}

Dimaksudkan untuk mengetahui secara langsung kondisi eksisting sarana dan prasarana drainase sebagai langkah awal untuk melakukan penelitian. Kemudian data dari hasil identfikasi tersebut, dilakukan evaluasi terhadap permasalahan yang terjadi sehingga dapat dilakukan rencana tindak lanjut.

\section{B. Studi Literatur}

Studi literatur dilakukan untuk mendapatkan dasar teori yang berkaitan dengan penelitian sehingga dapat menjadi acuan dalam melaksanakan penelitian. Literatur yang digunakan meliputi analisis hidrologi, perhitungan koefisien aliran rata-rata, penentuan PUH pada saluran primer dan sekunder, hidrologi saluran terbuka, sistem operasional rumah pompa, dan literatur lain yang menunjang.

\section{Pengumpulan Data}

Data yang dikumpulkan dalam penelitian merupakan data primer dan data sekunder. Data primer merupakan data yang didapat langsung dari survei lapangan. Data sekunder merupakan data yang diambil dari instansi-instansi yang berkaitan. 


\section{Pengolahan Data}

Pengolahan dilakukan setelah data primer dan sekunder yang diharapkan telah diperoleh. Pengolahan data dilakukan analisis hidrologi untuk memperoleh debit limpasan. Dilakukan perhitungan hidrolika untuk mengetahui debit saluran rencana dan debit eksisting. Selain itu, dilakukan perbandingan terhadap kapasitas pompa saat ini dan kapasitas awal.

\section{E. Analisis dan Pembahasan}

Analisis dan Pembahasan data dilakukan dengan melakukan evaluasi terhadap sistem operasional pemompaan di Rumah Pompa, debit saluran primer Kali Greges, dan debit 17 saluran sekunder dalam melayani debit aliran hujan. Setelah itu dilakukan analisis kapasitas pompa.

\section{F. Kesimpulan dan Saran}

Kesimpulan diperoleh berdasarkan hasil analisis dan pembahasan data perencanaan yang dilakukan sehingga diperoleh masalah utama yang menjadi penyebab masih timbulnya genangan pada wilayah studi yang dilayani oleh Rumah Pompa Greges yang kemudian ditetapkannya rencana tindak lanjut yang dilakukan. Selanjutnya menentukan saran untuk mengendalikan genangan yang timbul pada wilayah studi Sistem Pematusan Greges

\section{HASIL DAN PEMBAHASAN}

\section{A. Luas Area Sistem Pematusan Greges}

Berdasarkan kondisi topografi tersebut dilakukan pembagian blok pelayanan untuk setiap segmen di saluran primer dengan mempertimbangkan topografi di wilayah. maka diketahui luas masing-masing blok yang ditunjukkan pada Tabel 1 dan Gambar 1 [6].

$\underline{\text { Tabel } 1 \text { Luas Daerah Pelayanan Saluran Primer Kali Greges }}$

\begin{tabular}{ccc}
\hline $\begin{array}{c}\text { Kode Saluran } \\
\text { Primer Kali Greges }\end{array}$ & $\begin{array}{c}\text { Luas Daerah } \\
\text { (ha) }\end{array}$ & $\begin{array}{c}\text { Panjang } \\
(\mathrm{m})\end{array}$ \\
\hline A-B & 300,01 & 457 \\
B-C & 143,12 & 366 \\
C-D & 98,17 & 406 \\
D-E & 120,64 & 324 \\
E-F & 29,53 & 226 \\
F-G & 97,65 & 335 \\
G-H & 102,93 & 312 \\
H-I & 143,76 & 616 \\
I-J & 87,37 & 423 \\
J-K & 327,44 & 210 \\
K-L & 68,89 & 553 \\
Total & 1520 & 4228 \\
\hline
\end{tabular}

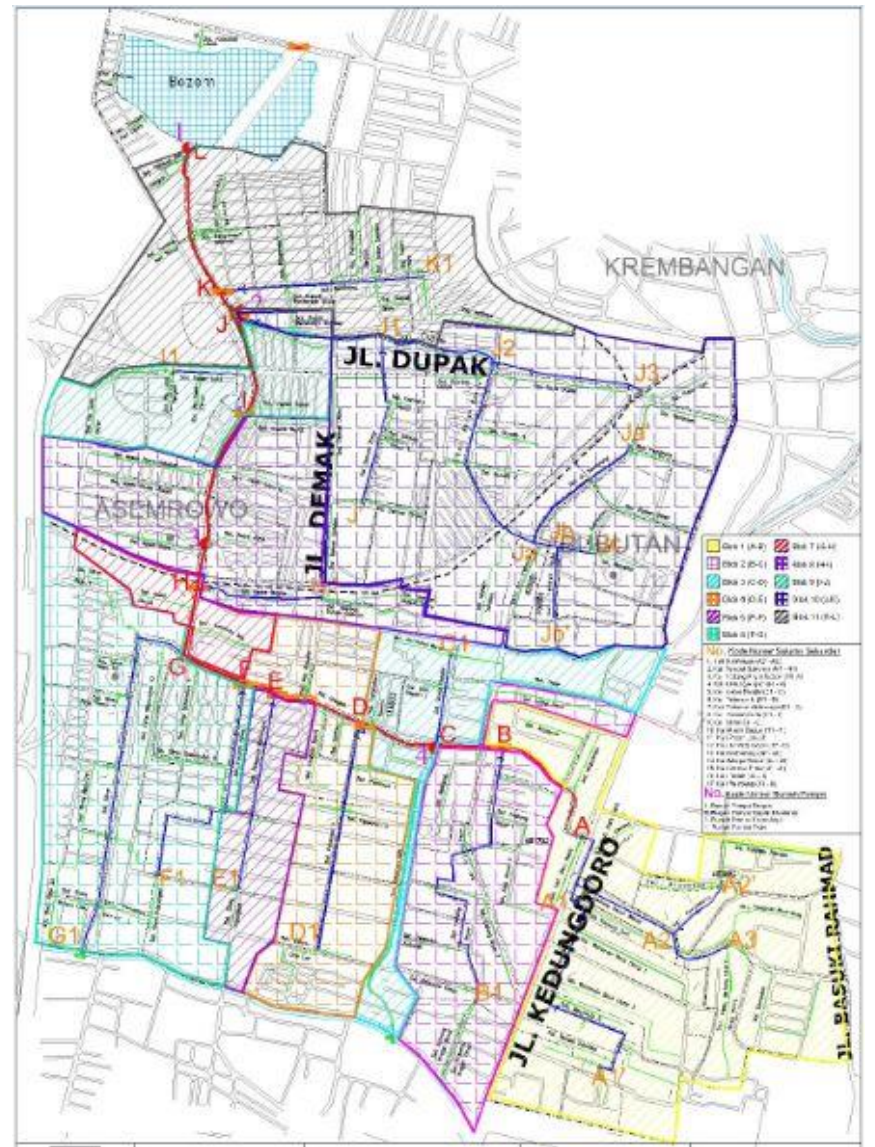

Gambar 1. Peta Sistem Pematusan Greges

\section{B. Perhitungan Debit Limpasan Hujan}

Penentuan besarnya debit limpasan tergantung pada besarnya intensitas hujan yang terjadi serta luas area dan fungsi tata guna lahan yang memberikan pengaruh pada nilai koefesien aliran. Dari fungsi tata guna lahan tersebut diketahui nilai koefesian aliran, sehingga didapatkan debit limpasan hujan yang ditunjukkan pada Tabel 2

Tabel 2. Hasil Perhitungan Debit Limpasan Hujan

\begin{tabular}{|c|c|c|c|c|}
\hline $\begin{array}{l}\text { Saluran } \\
\text { Sekunder }\end{array}$ & $\begin{array}{c}\text { A } \\
\text { limpasan } \\
\text { kumulatif } \\
\text { (ha) }\end{array}$ & $\begin{array}{l}\text { Koefesien } \\
\text { Aliran } \\
\text { Kumulatif }\end{array}$ & $\begin{array}{c}\text { Intensitas } \\
(\mathrm{mm} / \mathrm{jam}) \\
\text { PUH } 5\end{array}$ & $\begin{array}{c}\text { Qlimpasan } \\
\left(\mathrm{m}^{3} / \mathrm{dt}\right)\end{array}$ \\
\hline \multicolumn{5}{|c|}{ Kali Surabayan } \\
\hline $\mathrm{A} 22^{\prime}-\mathrm{A} 2$ & 79,19 & 0,81 & 30,83 & 0,55 \\
\hline \multicolumn{5}{|c|}{ Kali Tempel Sukorejo } \\
\hline A1'-A1 & 103,23 & 0,80 & 12,84 & 0,23 \\
\hline \multicolumn{5}{|c|}{ Kali Kedung Anyar Wetan } \\
\hline $\mathrm{A} 3-\mathrm{A} 2$ & 45,11 & 0,79 & 34,69 & 0,30 \\
\hline A2-A1 & 124,30 & 0,80 & 24,67 & 0,56 \\
\hline A1-A & 227,53 & 0,80 & 26,44 & 0,58 \\
\hline \multicolumn{5}{|c|}{ Kali Kedung Anyar } \\
\hline B1-B & 105,91 & 0,80 & 15,17 & 0,27 \\
\hline \multicolumn{5}{|c|}{ Kali Genie Pelajar } \\
\hline $\mathrm{C} 1-\mathrm{C}$ & 82,95 & 0,83 & 38,94 & 0,62 \\
\hline \multicolumn{5}{|c|}{ Kali Petemon V } \\
\hline D1-D & 90,83 & 0,77 & 16,91 & 0,25 \\
\hline
\end{tabular}




\begin{tabular}{|c|c|c|c|c|}
\hline \multicolumn{5}{|c|}{$\begin{array}{l}\text { Tabel } 2 . \\
\text { lanjutan }\end{array}$} \\
\hline $\begin{array}{l}\text { Saluran } \\
\text { Sekunder }\end{array}$ & $\begin{array}{c}\text { A limpasan } \\
\text { kumulatif } \\
\text { (ha) }\end{array}$ & $\begin{array}{c}\text { Koefesien } \\
\text { Aliran } \\
\text { Kumulatif }\end{array}$ & $\begin{array}{c}\text { Intensitas } \\
\text { (mm/jam) } \\
\text { PUH } 5\end{array}$ & $\begin{array}{c}\text { Qlimpasan } \\
\left(\mathrm{m}^{3} / \mathrm{dt}\right)\end{array}$ \\
\hline \multicolumn{5}{|c|}{ Kali Petemon Sidomulyo } \\
\hline E1-E & 102,93 & 0,77 & 18,89 & 0,32 \\
\hline \multicolumn{5}{|c|}{ Kali Pacuan Kuda } \\
\hline F1-F & 75,62 & 0,76 & 12,89 & 0,21 \\
\hline \multicolumn{5}{|l|}{ Kali Simo } \\
\hline G1-G & 102,93 & 0,77 & 29,38 & 0,56 \\
\hline \multicolumn{5}{|c|}{ Kali Asem Bagus } \\
\hline $\mathrm{H} 1-\mathrm{H}$ & 58,73 & 0,77 & 21,82 & 0,27 \\
\hline \multicolumn{5}{|c|}{ Kali Pasar Loak } \\
\hline I1-I & 90,83 & 0,77 & 31,32 & 0,49 \\
\hline \multicolumn{5}{|c|}{ Kali Tembok Gede } \\
\hline $\mathrm{Jb}^{\prime}-\mathrm{Jb}$ & 63,04 & 0,84 & 32,45 & 1,47 \\
\hline \multicolumn{5}{|c|}{ Kali Semarang } \\
\hline $\mathrm{Ja}^{\prime}-\mathrm{Ja}$ & 44,74 & 0,76 & 18,73 & 1,39 \\
\hline \multicolumn{5}{|c|}{ Kali Margo Rukun } \\
\hline $\mathrm{Jc}-\mathrm{Jb}$ & 5,74 & 0,82 & 49,10 & 2,36 \\
\hline $\mathrm{Jb}-\mathrm{Ja}$ & 68,78 & 0,83 & 33,63 & 2,74 \\
\hline Ja-J2 & 120,88 & 0,81 & 23,96 & 2,82 \\
\hline \multicolumn{5}{|c|}{ Kali Demak Timur } \\
\hline $\mathrm{J}^{\prime}-\mathrm{J} 1$ & 234,71 & 0,83 & 17,35 & 0,94 \\
\hline \multicolumn{5}{|l|}{ Kali Dupak } \\
\hline $\mathrm{J} 3-\mathrm{J} 2$ & 5,75 & 0,80 & 30,64 & 3,33 \\
\hline J2-J1 & 126,63 & 0,81 & 24,70 & 3,89 \\
\hline $\mathrm{J} 1-\mathrm{J}$ & 361,34 & 0,82 & 24,05 & 4,14 \\
\hline \multicolumn{5}{|c|}{ Kali Rembang } \\
\hline K1-K & 45,78 & 0,79 & 28,75 & 0,29 \\
\hline $\begin{array}{l}\text { Saluran } \\
\text { Primer }\end{array}$ & $\begin{array}{c}\text { A } \\
\text { limpasan } \\
\text { kumulatif } \\
\text { (ha) }\end{array}$ & $\begin{array}{l}\text { Koefesien } \\
\text { Aliran } \\
\text { Kumulatif }\end{array}$ & 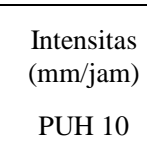 & $\begin{array}{c}\text { Qlimpasan } \\
\left(\mathrm{m}^{3} / \mathrm{dt}\right)\end{array}$ \\
\hline A-B & 266,86 & 0,80 & 27,58 & 1,56 \\
\hline B-C & 409,98 & 0,80 & 31,02 & 2,73 \\
\hline C-D & 508,23 & 0,80 & 33,71 & 3,70 \\
\hline D-E & 628,87 & 0,79 & 33,59 & 4,56 \\
\hline E-F & 658,40 & 0,79 & 50,97 & 7,20 \\
\hline F-G & 756,05 & 0,79 & 39,23 & 8,83 \\
\hline G-H & 858,98 & 0,79 & 39,34 & 8,87 \\
\hline H-I & 1002,87 & 0,78 & 33,66 & 9,47 \\
\hline I-J & 1090,23 & 0,78 & 38,89 & 8,95 \\
\hline $\mathrm{J}-\mathrm{K}$ & 1451,57 & 0,79 & 27,24 & 8,63 \\
\hline K-L & 1520 & 0,78 & 39,26 & 12,23 \\
\hline
\end{tabular}

\section{Perhitungan Kapasitas Saluran}

Kapasitas saluran primer Kali Greges dan 17 saluran sekunder yang ada pada wilayah studi dihitung berdasarkan kondisi yang ada di lapangan yaitu dimulai saat belum terdapat sedimen (rencana) hingga kondisi saluran saat ini (eksisting) yaitu telah terdapat sedimen. Pengukuran ketebalan sedimen dengan menggunakan tongkat dan kecepatan aliran dengan menggunakan metode apung [1]. Hasil perhitungan kapasitas saluran ditunjukkan pada Tabel 3 .

Tabel 3 .

Hasil Perhitungan Kapasitas Saluran

\begin{tabular}{|c|c|c|c|c|c|}
\hline \multicolumn{6}{|c|}{ Saluran Sekunder } \\
\hline \multicolumn{2}{|c|}{ Luas (m2) } & \multicolumn{2}{|c|}{ Kapasitas Saluran $\left(\mathrm{m}^{3}\right)$} & \multicolumn{2}{|c|}{ Debit $\left(\mathrm{m}^{3} / \mathrm{dt}\right)$} \\
\hline Rencana & Eksisting & Rencana & Eksisting & Rencana & Eksisting \\
\hline \multicolumn{6}{|c|}{ Kali Surabayan (A2'-A2) } \\
\hline 10,55 & 9,82 & 6497 & 6052 & 2,37 & 1,31 \\
\hline \multicolumn{6}{|c|}{ Kali Tempel Sukorejo (A1'-A1) } \\
\hline 15,51 & 14,80 & 36899 & 35205 & 2,79 & 2,22 \\
\hline \multicolumn{6}{|c|}{ Kali Kedung Anyar Wetan (A3-A) } \\
\hline 13,92 & 13,17 & 8325 & 7879 & 6,08 & 1,76 \\
\hline 12,64 & 11,93 & 12030 & 11353 & 3,70 & 1,79 \\
\hline 12,19 & 11,56 & 7097 & 6728 & 3,46 & 1,93 \\
\hline \multicolumn{6}{|c|}{ Kali Kedung Anyar (B1-B) } \\
\hline 15,08 & 14,20 & 44756 & 42130 & 3,19 & 2,84 \\
\hline \multicolumn{6}{|c|}{ Kali Genie Pelajar (C1-C) } \\
\hline 11,19 & 10,64 & 9066 & 8618 & 4,91 & 2,66 \\
\hline \multicolumn{6}{|c|}{ Kali Petemon V (D1-D) } \\
\hline 11,28 & 10,55 & 23414 & 21910 & 2,46 & 1,58 \\
\hline \multicolumn{6}{|c|}{ Kali Petemon Sidomulyo (E1-E) } \\
\hline 8,17 & 7,59 & 14291 & 13267 & 1,49 & 1,14 \\
\hline \multicolumn{6}{|c|}{ Kali Pacuan Kuda (F1-F) } \\
\hline 8,76 & 8,10 & 25341 & 23422 & 1,47 & 1,08 \\
\hline \multicolumn{6}{|c|}{ Kali Simo (G1-G) } \\
\hline 43,56 & 37,17 & 94227 & 80392 & 38,77 & 24,16 \\
\hline \multicolumn{6}{|c|}{ Kali Asem Bagus (H1-H) } \\
\hline 18,28 & 16,93 & 20293 & 18795 & 3,62 & 2,54 \\
\hline \multicolumn{6}{|c|}{ Kali Pasar Loak (I1-I) } \\
\hline 11,01 & 10,13 & 11172 & 10281 & 3,52 & 2,19 \\
\hline \multicolumn{6}{|c|}{ Kali Tembok Gede (Jb'Jb) } \\
\hline 9,86 & 9,21 & 6081 & 5682 & 3,10 & 1,07 \\
\hline \multicolumn{6}{|c|}{ Kali Semarang (Ja'-Ja) } \\
\hline 10,92 & 10,20 & 13238 & 12364 & 1,42 & 1,02 \\
\hline \multicolumn{6}{|c|}{ Kali Margo Rukun (Jc-Jb), (Jb-Ja), (Ja-J2) } \\
\hline 15,01 & 13,96 & 6782 & 6310 & 3,88 & 2,33 \\
\hline 14,20 & 13,27 & 6122 & 5720 & 3,16 & 2,65 \\
\hline 12,27 & 11,29 & 18728 & 17231 & 3,58 & 2,45 \\
\hline \multicolumn{6}{|c|}{ Kali Demak Timur (J'-J1) } \\
\hline 7,61 & 6,94 & 11501 & 10491 & 1,09 & 0,93 \\
\hline \multicolumn{6}{|c|}{ Kali Dupak (J3-J2), (J2-J1), (J1-J) } \\
\hline 18,24 & 16,56 & 24111 & 21892 & 3,58 & 3,31 \\
\hline 17,29 & 15,71 & 17755 & 16134 & 5,12 & 3,67 \\
\hline 14,44 & 12,81 & 19524 & 17320 & 6,86 & 3,84 \\
\hline \multicolumn{6}{|c|}{ Kali Rembang (K1-K) } \\
\hline 13,25 & 12,27 & 1512,00 & 3,20 & 2,90 & 0,03 \\
\hline
\end{tabular}


Tabel 3.

lanjutan

\begin{tabular}{|c|c|c|c|c|c|}
\hline \multicolumn{6}{|c|}{ Saluran Primer } \\
\hline \multicolumn{2}{|c|}{ Luas (m2) } & \multicolumn{2}{|c|}{$\begin{array}{c}\text { Kapasitas Saluran } \\
\left(\mathrm{m}^{3}\right)\end{array}$} & \multicolumn{2}{|c|}{ Debit $\left(\mathrm{m}^{3} / \mathrm{dt}\right)$} \\
\hline Rencana & Eksisting & Rencana & Eksisting & Rencana & Eksisting \\
\hline \multicolumn{6}{|l|}{ A-B } \\
\hline 21,19 & 16,18 & 9683 & 7395 & 10,04 & 5,93 \\
\hline \multicolumn{6}{|l|}{$B-C$} \\
\hline 22,45 & 16,33 & 8218 & 5976 & 9,35 & 7,62 \\
\hline \multicolumn{6}{|l|}{ C-D } \\
\hline 22,74 & 16,38 & 9232 & 6650 & 9,91 & 8,74 \\
\hline \multicolumn{6}{|l|}{ D-E } \\
\hline 23,93 & 17,19 & 7753 & 5570 & 12,55 & 10,03 \\
\hline \multicolumn{6}{|l|}{ E-F } \\
\hline 25,14 & 18,38 & 5681 & 4153 & 16,96 & 11,03 \\
\hline \multicolumn{6}{|l|}{ F-G } \\
\hline 25,63 & 17,94 & 8585 & 6010 & 21,75 & 10,76 \\
\hline \multicolumn{6}{|l|}{ G-H } \\
\hline 26,00 & 17,98 & 8112 & 5611 & 23,23 & 11,39 \\
\hline \multicolumn{6}{|l|}{ H-I } \\
\hline 25,97 & 17,34 & 15996 & 10679 & 22,34 & 12,14 \\
\hline \multicolumn{6}{|l|}{ I-J } \\
\hline 25,96 & 16,16 & 10983 & 6835 & 23,30 & 11,85 \\
\hline \multicolumn{6}{|l|}{$\mathrm{J}-\mathrm{K}$} \\
\hline 25,72 & 16,04 & 5401 & 3368 & 24,63 & 12,03 \\
\hline \multicolumn{6}{|l|}{ K-L } \\
\hline 25,25 & 15,35 & 13966 & 8486 & 24,63 & 12,03 \\
\hline
\end{tabular}

D. Perbandingan Kapasitas Saluran Eksisting Dengan Debit Limpasan

Berdasarkan Tabel 3, diketahui kapasitas saluran eksisting yaitu dengan adanya sedimen. Berdasarkan Tabel 2 diketahui debit limpasan menuju saluran untuk setiap segmen baik di saluran primer dan sekunder, kemudian kedua nilai tersebut dibandingkan untuk mengetahui kemampuan kapasitas saluran eksisting dalam melayani debit limpasan hujan. Perbandingan antara kapasitas saluran eksisting dengan debit limpasan ditunjukkan pada Tabel 4.

Tabel 4.

Hasil Perbandingan Kapasitas Saluran Eksisting Dengan Debit Limpasan

\begin{tabular}{|c|c|c|c|c|}
\hline \multirow{2}{*}{$\begin{array}{l}\text { Saluran } \\
\text { Sekunder }\end{array}$} & Qlimpasan & $\begin{array}{l}\text { Qsaluran } \\
\text { Eksisting }\end{array}$ & Qsisa & \multirow[t]{2}{*}{ Kesimpulan } \\
\hline & $\left(\mathrm{m}^{3} / \mathrm{dt}\right)$ & $\left(\mathrm{m}^{3} / \mathrm{dt}\right)$ & $\left(\mathrm{m}^{3} / \mathrm{dt}\right)$ & \\
\hline \multicolumn{4}{|c|}{ Kali Surabayan } & \multirow{2}{*}{ Memenuhi } \\
\hline A2'-A2 & 0,55 & 1,31 & 0,76 & \\
\hline \multicolumn{4}{|c|}{ Kali Tempel Sukorejo } & \multirow{2}{*}{ Memenuhi } \\
\hline $\mathrm{A} 11^{\prime}-\mathrm{A} 1$ & 0,23 & 2,22 & 1,99 & \\
\hline
\end{tabular}

Tabel 4.

lanjutan

\begin{tabular}{ccccc}
\hline $\begin{array}{c}\text { Saluran } \\
\text { Sekunder }\end{array}$ & $\begin{array}{c}\text { Qlimpasan } \\
\left(\mathrm{m}^{3} / \mathrm{dt}\right)\end{array}$ & $\begin{array}{c}\text { Qsaluran } \\
\text { Eksisting } \\
\left(\mathrm{m}^{3} / \mathrm{dt}\right)\end{array}$ & $\begin{array}{c}\text { Qsisa } \\
\left(\mathrm{m}^{3} / \mathrm{dt}\right)\end{array}$ & Kesimpulan \\
\hline \multicolumn{2}{l}{ Kali Kedung Anyar Wetan } & & & \\
A3-A2 & 0,30 & 1,76 & 1,46 & Memenuhi \\
A2-A1 & 0,56 & 1,79 & 1,23 & \\
A1-A & 0,58 & 1,93 & 1,35 &
\end{tabular}

Kali Kedung Anyar

$\begin{array}{lllll}\text { B1-B } & 0,27 & 2,84 & 2,57 & \text { Memenuhi }\end{array}$

Kali Genie Pelajar

$\begin{array}{llll}\text { C1-C } \quad 0,62 & 2,66 & 2,04\end{array}$

Memenuhi

Kali Petemon V

$\begin{array}{llll}\text { D1-D } & 0,25 & 1,58 & 1,34\end{array}$

Memenuhi

Kali Petemon Sidomulyo

Memenuhi

$\begin{array}{llll}\text { E1-E } & 0,32 & 1,14 & 0,82\end{array}$

Kali Pacuan Kuda

$\begin{array}{llll}\text { F1-F } & 0,21 & 1,08 & 0,87\end{array}$

Kali Simo

$\begin{array}{llll}\text { G1-G } & 0,56 & 24,16 & 23,59\end{array}$

Kali Asem Bagus

$\begin{array}{ccccc}\text { H1-H } & 0,27 & 2,54 & 2,27 & \\ \text { Kali Pasar Loak } & & & & \text { Memenuhi } \\ \text { I1-I } & 0,49 & 2,19 & 1,70 & \end{array}$

Kali Tembok Gede

$\begin{array}{lcccc}\begin{array}{l}\text { Jb'-Jb } \\ \text { Kali Semarang }\end{array} & 1,47 & 1,07 & -0,40 & \begin{array}{c}\text { Memenuhi } \\ \text { Ja'-Ja }\end{array} \\ \begin{array}{llll}\text { Tidak } \\ \text { Kali Margo Rukun } \\ \text { Jc -Jb }\end{array} & 1,39 & 1,02 & -0,37 & \text { Memenuhi } \\ \text { Jb-Ja } & 2,36 & 2,33 & -0,03 & \begin{array}{c}\text { Tidak } \\ \text { Ja-J2 }\end{array} \\ \text { Memenuhi }\end{array}$

Kali Demak Timur

Tidak

$\begin{array}{lllll}\text { J'-J1 } & 0,94 & 0,93 & -0,02 & \text { Memenuhi }\end{array}$

Kali Dupak

$\begin{array}{ccccc}\text { J3-J2 } & 3,33 & 3,31 & -0,02 & \begin{array}{c}\text { Tidak } \\ \text { J2-J1 }\end{array} \\ \text { J1-J } & 3,89 & 3,67 & -0,22 & \\ \text { Hemenuhi }\end{array}$

Kali Rembang

K1-K

0,29

2,66

2,37

Memenuhi

\begin{tabular}{ccccc} 
K1-K & 0,29 & 2,66 & 2,37 & \\
\hline $\begin{array}{c}\text { Saluran } \\
\text { Primer }\end{array}$ & Qlimpasan & $\begin{array}{c}\text { Qsaluran } \\
\text { Eksisting } \\
\left(\mathrm{m}^{3} / \mathrm{dt}\right)\end{array}$ & $\begin{array}{c}\text { Qsisa }) \\
\left(\mathrm{m}^{3} / \mathrm{dt}\right)\end{array}$ & Kesimpulan \\
\hline A-B & 1,56 & 0,47 & 4,37 & Memenuhi \\
B-C & 2,73 & 0,42 & 4,89 & Memenuhi \\
C-D & 3,70 & 0,44 & 5,04 & Memenuhi \\
D-E & 4,56 & 0,52 & 5,47 & Memenuhi \\
E-F & 7,20 & 0,67 & 3,82 & Memenuhi \\
F-G & 8,83 & 0,85 & 1,93 & Memenuhi \\
G-H & 8,87 & 0,89 & 2,52 & Memenuhi \\
H-I & 9,47 & 0,86 & 2,67 & Memenuhi \\
\hline
\end{tabular}




\begin{tabular}{|c|c|c|c|c|}
\hline & & $\begin{array}{l}\text { Tabel } 4 . \\
\text { lanjutan }\end{array}$ & & \\
\hline $\begin{array}{c}\text { Saluran } \\
\text { Primer }\end{array}$ & $\begin{array}{c}\text { Qlimpasan } \\
\left(\mathrm{m}^{3} / \mathrm{dt}\right)\end{array}$ & $\begin{array}{c}\text { Qsaluran } \\
\text { Eksisting } \\
\left(\mathrm{m}^{3} / \mathrm{dt}\right)\end{array}$ & $\begin{array}{l}\text { Qsisa } \\
\left(\mathrm{m}^{3} / \mathrm{dt}\right)\end{array}$ & Kesimpulan \\
\hline I-J & 8,95 & 0,90 & 2,90 & Memenuhi \\
\hline $\mathrm{J}-\mathrm{K}$ & 8,63 & 0,96 & 3,40 & Memenuhi \\
\hline K-L & 12,23 & 0,90 & 0,05 & Memenuhi \\
\hline
\end{tabular}

Diketahui bahwa kelima saluran sekunder tidak dapat melayani debit limpasan hujan. Berdasarkan hasil observasi tanggal 16 April 2016 yang merupakan salah satu bencana banjir atau genangan di wilayah studi, diketahui dari hasil perhitungan yaitu lama genangan maksimum yaitu 4 jam, tinggi genangan maksimum $40 \mathrm{~cm}$, dan total luas genangan 5,71 ha. Berikut adalah peta genangan Sistem Pematusan Greges seluruhnya di dalam dan luar ruang lingkup penelitian yang ditunjukkan pada Gambar 2.

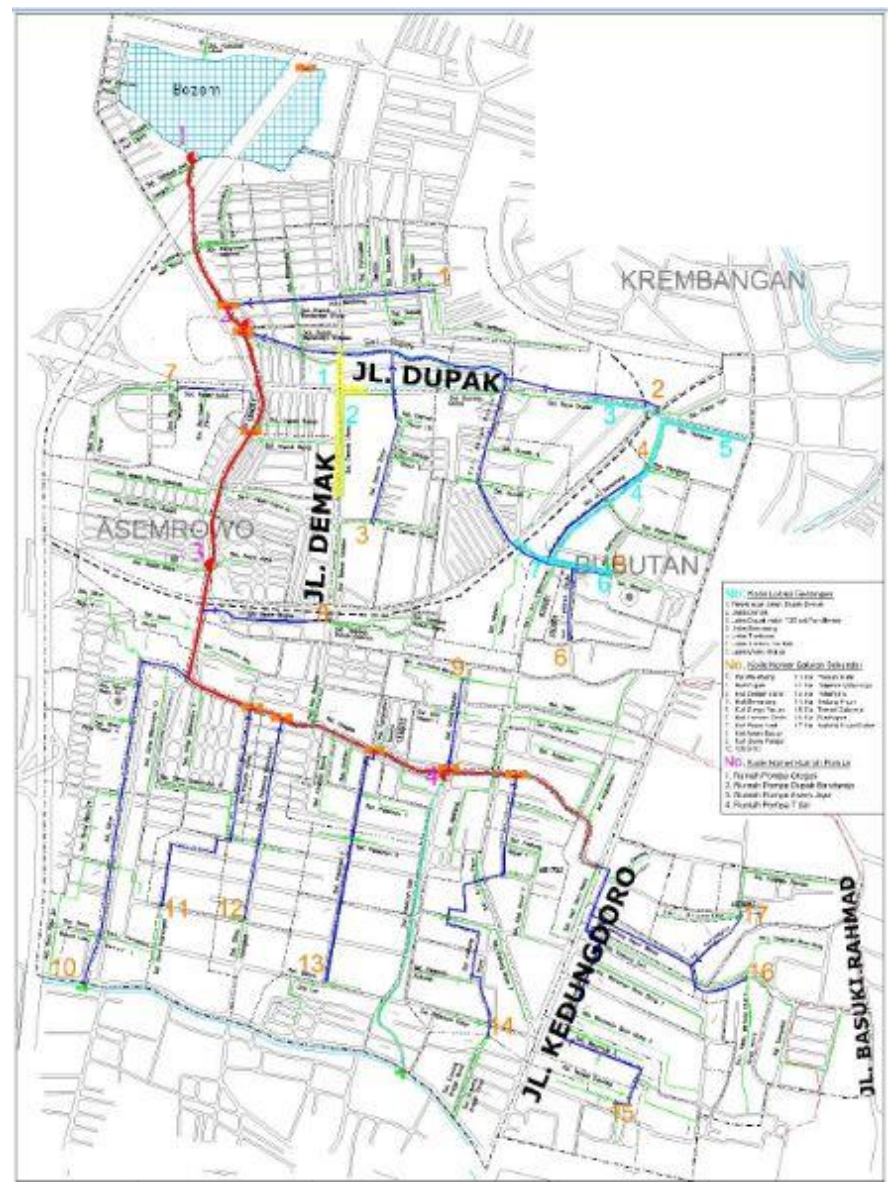

Gambar 2. Peta Genangan Sistem Pematusan Greges 2016

\section{E. Analisis Kapasitas Pompa Banjir}

Pada analisis pompa ini dilakukan analisis dengan membandingkan kapasitas awal pompa dengan kapasitas pompa eksisting. Kapasitas awal pompa didapat dari instansi terkait, sedangkan kapasitas pompa eksisting didapatkan dari laporan pemilaharaan yang dilakukan setiap tahunnya yang didapat dari instansi terkait [4]. Berikut adalah perhitungan kapasitas pompa eksisting dalam melayani volume genangan 5 yang ditunjukkan pada Tabel 5 .
Tabel 5.

Perbandingan Kapasitas Pompa

\begin{tabular}{|c|c|c|c|c|c|}
\hline $\begin{array}{l}\text { Nama } \\
\text { Rumah } \\
\text { Pompa }\end{array}$ & Pelayanan & $\begin{array}{l}\text { Tahun } \\
\text { Operasi }\end{array}$ & $\begin{array}{c}\text { Jumlah } \\
\text { Pompa } \\
\text { Banjir } \\
\\
\text { (Unit) } \\
\end{array}$ & $\begin{array}{c}\text { Total } \\
\text { Kapasitas } \\
\text { Pompa } \\
\text { Banjir } \\
\text { Awal } \\
\text { (m3) } \\
\end{array}$ & $\begin{array}{c}\text { Kapasita } \\
\text { s Pompa } \\
\text { Tahun } \\
2015 \text { [4] } \\
\text { (m3) } \\
\end{array}$ \\
\hline $\begin{array}{c}\text { Dupak } \\
\text { Bandarejo }\end{array}$ & $\begin{array}{c}\text { Saluran } \\
\text { Sekunder } \\
\text { Kali } \\
\text { Dupak }\end{array}$ & 2004 & 3 & 4,5 & 3,6 \\
\hline Greges & $\begin{array}{c}\text { Saluran } \\
\text { Primer } \\
\text { Kali } \\
\text { Greges }\end{array}$ & 2012 & 6 & 13 & 11,5 \\
\hline
\end{tabular}

\section{F. Analisis Pengerukan Sedimen}

Pengerukan sedimen merupakan salah satu rencana tindak lanjut yang menjadi prioritas untuk dilakukan. Berikut perhitungan yang menunjukkan bahwa apabila saluran sekunder yang tidak mampu melayani debit limpasan apabila dilakukan pengerukan kelima saluran sekunder tersebut mampu menampung limpasan hujan yang ditunjukkan pada Tabel 6.

Tabel 6.

Hasil Perhitungan Pengerukan Sedimen

\begin{tabular}{|c|c|c|c|c|c|}
\hline \multirow{2}{*}{$\begin{array}{c}\text { Saluran } \\
\text { Sekunder }\end{array}$} & $\begin{array}{c}\text { Volume } \\
\text { Sedimen }\end{array}$ & Qrencana & $\begin{array}{c}\mathrm{Q} \\
\text { limpasan }\end{array}$ & Qsisa & \multirow[t]{2}{*}{ Keterangan } \\
\hline & $\mathrm{m}^{3}$ & $\mathrm{~m}^{3} / \mathrm{dt}$ & $\mathrm{m}^{3} / \mathrm{dt}$ & $\mathrm{m}^{3} / \mathrm{dt}$ & \\
\hline \multicolumn{5}{|c|}{ Kali Tembok Gede } & \multirow{2}{*}{ Memenuhi } \\
\hline $\mathrm{Jb}^{\prime}-\mathrm{Jb}$ & 399 & 3,10 & 1,47 & 1,63 & \\
\hline \multicolumn{5}{|c|}{ Kali Semarang } & \multirow{2}{*}{ Memenuhi } \\
\hline $\mathrm{Ja}^{\prime}-\mathrm{Ja}$ & 874 & 1,42 & 1,39 & 0,03 & \\
\hline \multicolumn{6}{|c|}{ Kali Margo Rukun } \\
\hline $\mathrm{Jc}-\mathrm{Jb}$ & 473 & 3,88 & 2,36 & 1,52 & \multirow{3}{*}{ Memenuhi } \\
\hline $\mathrm{Jb}-\mathrm{Ja}$ & 402 & 3,16 & 2,74 & 0,42 & \\
\hline Ja-J2 & 1497 & 3,58 & 2,82 & 0,76 & \\
\hline \multicolumn{5}{|c|}{ Kali Demak Timur } & \multirow{2}{*}{ Memenuhi } \\
\hline $\mathrm{J}^{\prime}-\mathrm{J} 1$ & 1010 & 1,09 & 0,94 & 0,14 & \\
\hline \multicolumn{6}{|c|}{ Kali Dupak } \\
\hline J3-J2 & 2218 & 3,58 & 3,33 & 0,25 & \multirow{4}{*}{ Memenuhi } \\
\hline $\mathrm{J} 2-\mathrm{J} 1$ & 1621 & 5,12 & 3,89 & 1,23 & \\
\hline $\mathrm{J} 1-\mathrm{J}$ & 2204 & 6,86 & 4,14 & 2,72 & \\
\hline Total & 10697 & & & & \\
\hline
\end{tabular}

G. Analisis Standard Operating Procedure (SOP)

Pengoperasian Pompa Eksisting

Pada catchment area Sistem Pematusan tidak ada Standard Operating Procedure (SOP) pengoperasian pompa secara tertulis. Berikut adalah rumah pompa sistem pematusan Greges yang dekat dengan laut, antara lain:

1. Rumah Pompa Asem Jaya yang melayani saluran tersier Kali Asem Jaya.

2. Rumah Pompa Dupak Bandarejo yang melayani saluran sekunder Kali Dupak.

3. Rumah Pompa Greges yang melayani saluran primer Kali Greges. 
4. Rumah Pompa Gadukan yang melayani Boezem Morokrembangan Selatan.

5. Rumah Pompa Morokrembangan yang melayani Boezem Morokrembangan Utara

Berikut adalah alur pengoperasian pompa Sistem Pematusan Greges yang ditunjukkan pada Gambar 3.

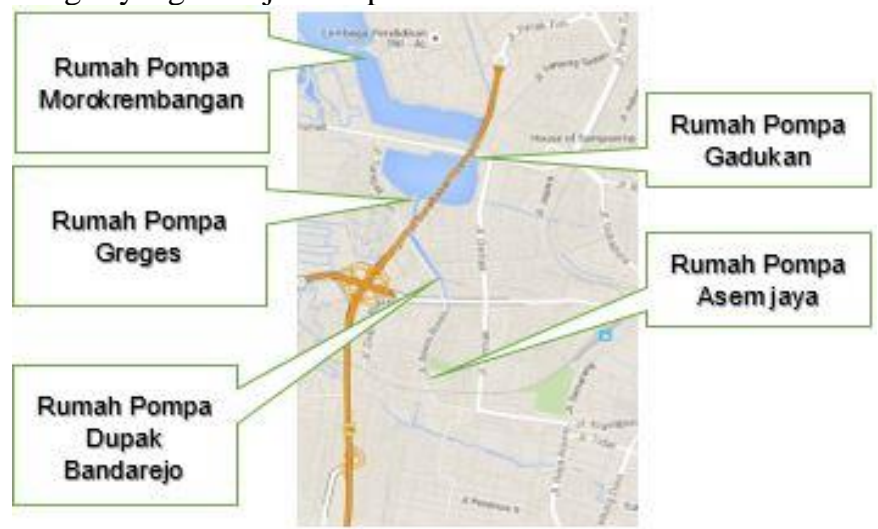

Gambar 3. Alur Pengoperasian Pompa Banjir Sistem Pematusan Greges 2016

Berdasarkan kondisi di lapangan pengoperasian pompa banjir dibedakan menjadi 3 kondisi, antara lain:

1. Kondisi sebelum terjadi laut pasang dan turunnya hujan.

2. Kondisi saat terjadi laut pasang dan turunnya hujan.

3. Kondisi setelah terjadi laut pasang dan turunnya hujan.

Meskipun telah adanya pengoperasian pompa dari segi kondisi, namun ada perbedaan pendapat dalam pengoperasian pompa yaitu

1. Keputusan dilakukannya pengoperasian pompa banjir dengan melihat tinggi muka air di saluran, boezem, dan laut.

2. Keputusan dalam menentukan waktu yang dibutuhkan saat pompa dioperasikan.

\section{KESIMPULAN/RINGKASAN}

1. Hasil analisis dan pembahasan peyebab timbulnya genangan pada catchment area Sistem pematusan Greges adalah

a) Saluran sekunder Kali Tembok Gede, Kali Semarang, Kali Margo Rukun, Kali Demak Timur, dan Kali Dupak tidak mampu menampung debit limpasan hujan, sehingga terjadi genangan dengan tinggi genangan maksimum $40 \mathrm{~cm}$, lama genangan maksimum 240 menit, dan total luas genangan 5,71 ha.

b) Saluran primer Kali Greges dengan adanya sedimen saat ini yaitu $12,28 \mathrm{~m}^{3} /$ detik, sedangkan debit limpasan hujan yaitu 12,23 $\mathrm{m}^{3} /$ detik sehingga masih mampu menampung debit limpasan hujan yang masuk ke dalam Saluran Primer Kali Greges.

c) Kapasitas total pompa banjir pada Rumah Pompa Dupak Bandarejo dalam waktu 12 tahun yang melayani saluran sekunder Kali Dupak yang merupakan muara dari 4 saluran sekunder yaitu Kali Demak Timur, Kali Margo Rukun, Kali Semarang, dan Kali Tembok Gede terjadi penurunan kinerja dari 4,5 $\mathrm{m}^{3} /$ detik menjadi $3,6 \mathrm{~m}^{3} /$ detik dari hasil laporan pemeliharaan pompa tahun 2015 .

d) Kapasitas total pompa banjir pada Rumah Pompa
Greges dalam waktu 4 tahun.yang melayani saluran primer Kali Greges terjadi penurunan kinerja dari 13 $\mathrm{m}^{3} /$ detik menjadi $12,5 \mathrm{~m}^{3} /$ detik dari hasil laporan pemeliharaan pompa tahun 2015.

e) Tidak adanya Standard Operating Procedure (SOP) Pengoperasian Sistem Pematusan Greges secara tertulis.

2. Hasil rencana tindak lanjut dan saran yang dilakukan dari analisis dan pembahasan dalam mengurangi genangan pada catchment area Sistem pematusan Greges adalah

a) Dilakukan pengerukan sedimen pada 5 segmen saluran sekunder yaitu Kali Tembok Gede, Kali Semarang, Kali Margo Rukun, Kali Demak Timur, dan Kali Dupak, agar saluran pada segmen tersebut dapat menampung debit limpasan air hujan yang masuk.

b) Adanya Standard Operating Procedure (SOP) Pengoperasian Pompa pada catchment area Sistem Pematusan Greges secara lisan dari hasil diskusi dengan Kepala Rayon Genteng.

c) Perlu dilakukan rehabilitasi maupun normalisasi sarana dan prasarana Sistem Pematusan Greges antara lain pada saluran primer, saluran sekunder, saluran tersier, rumah pompa, dan boezem morokrembangan selatan dan utara.

d) Perlu adanya pompa non permanen yang telah disiapkan untuk ditempatkan di lokasi yang rawan genangan pada catchment area Sistem Pematusan Greges untuk mengurangi genangan lebih cepat.

e) Perlu adanya Standard Operating Procedure (SOP) secara menyeluruh, meliputi normalisasi saluran dan boezem, waktu operasional dan pemeliharaan sarana dan prasarana rumah pompa, dan lain sebagainya pada catchment area Sistem Pematusan Greges.

f) Pada evaluasi berikutnya di wilayah studi, diperlukan analisis dan pembahasan pada saluran tersier.

\section{UCAPAN TERIMA KASIH}

Penulis mengucapkan terima kasih kepada dosen pembimbing dan dosen penguji Tugas Akhir atas saran dan masukan terhadap penulisan jurnal dan kepada instansiinstansi yang telah memberikan perijinan dan pengambilan data serta angkatan 2012 yang telah memberikan semangat penulis selama masa perkuliahan.

\section{DAFTAR PUSTAKA}

[1] Badan Standarisasi Nasional (BSN). 2015. Tata Cara Pengukuran Debit Aliran Sungai dan Saluran Terbuka Menggunakan Alat Ukur Arus dan Penampung. SNI 8066-2015. Jakarta. Indonesia

[2] Badan Pusat Statistik Kota Surabaya. 2015. Laporan Statistik Surabaya Dalam Angka Tahun 2015. Surabaya. Indonesia

[3] Badan Perencanaan Pembangunan Kota Surabaya. 2015. Laporan Perencanaan Pembangunan Kota Surabaya Tahun 2009-2029. Surabaya. Indonesia

[4] Dinas Bina Marga dan Pematusan Surabaya. 2015. Surabaya Drainage Masterplan 2018. Surabaya, Indonesia

[5] Subarkah Ir. 1980. Hidrologi Untuk Perencanaan Bangunan Air. Ide Dahrma, Bandung. Indonesia.

[6] UPT PSAWS Buntung Peketingan.2015. Laporan Data Curah Hujan Stasiun Kota Surabaya 2000-2015. Surabaya. Indonesia 